\title{
Wettability of SiC by Liquid Pure Metals*
}

\author{
By Kiyoshi Nogi** and Kazumi Ogino**
}

\begin{abstract}
The wettability of three kinds of $\mathrm{SiC}$ such as a reaction bonded $\mathrm{SiC}$, a hot pressed $\mathrm{SiC}$ and a single crystal of $\alpha$-SiC by liquid metals ( $\mathrm{Pb}, \mathrm{Sn}, \mathrm{Al}, \mathrm{Si}, \mathrm{Au}, \mathrm{Ge}, \mathrm{Ag}, \mathrm{Fe}, \mathrm{Ni}$ and $\mathrm{Co}$ ) was measured by the sessile drop method. Wettability was evaluated by the contact angle of liquid metal on $\mathrm{SiC}$.

The main results obtained are as follows: ined.

(1) Contact angles of liquid pure $\mathrm{Pb}, \mathrm{Sn}, \mathrm{Au}$ and $\mathrm{Ag}$ were larger than $90^{\circ}$ for all kinds of $\mathrm{SiC}$ exam-

(2) Reactivity of reaction bonded SiC with liquid metals may be controlled by the carbon treatment, which carburates the surface of the SiC.

(3) Contact angles of liquid pure $\mathrm{Fe}, \mathrm{Co}$ and $\mathrm{Ni}$ were always smaller than $90^{\circ}$ for both the reaction bonded $\mathrm{SiC}$ and the hot pressed $\mathrm{SiC}$.

(4) Contact angle of liquid pure $\mathrm{Al}$ on a single crystal of $\alpha$-SiC changed considerably with time elapsing. The initial contact angle was $160^{\circ}$, reducing gradually with time, the final one after $6.9 \mathrm{ks}$ was $56^{\circ}$.

(5) Contact angle of liquid pure Ge depended on the kind of SiC used. The contact angle was obtuse on hot pressed $\mathrm{SiC}$ and $\alpha-\mathrm{SiC}$, while it was acute on reaction bonded $\mathrm{SiC}$.

(6) Wetting behavior of liquid metals on SiC closely is related to the solubility of Si and C.
\end{abstract}

(Received May 12, 1988)

Keywords: contact angle, wetting, wettability, FRM, SiC, composites, liquid metal

\section{Introduction}

Recently, ceramics have come into use in many fields, because they have excellent properties of heat-resistance, high-temperature strength, and corrosion resistance. Particularly, as $\mathrm{SiC}$ and $\mathrm{Si}_{3} \mathrm{~N}_{4}$ are composed of elements which exist in sufficient abundance, it may be expected that the demand for them will increase. However, ceramics are generally weak in thermal shocks and difficult to sinter, and using them with metals and composites are of importance in solving these problems.

The wettability of ceramics by liquid metals is one of the most important properties for metal-ceramic joinings and the production of composites. However, systematic research on the wettability of ceramics by liquid metals is scarce and considerable differences are noticeable among the values reported. This

* A part of this paper was originally published in Japanese in J. Japan Inst. Metals, 52 (1988), 786.

** Department of Materials Science and Processing, Faculty of Engineering, Osaka University, Suita 565, Japan. could be caused by the difficulty of measuring wettability at high temperature, and wettability being affected by the presence of small amounts of impurities.

In this work, the wettability of various $\mathrm{SiC}$ (reaction bonded $\mathrm{SiC}$, hot pressed $\mathrm{SiC}$ and single crystal of $\alpha$-SiC) by liquid pure metals ( $\mathrm{Pb}, \mathrm{Sn}, \mathrm{Al}, \mathrm{Si}, \mathrm{Au}, \mathrm{Ge}, \mathrm{Ag}, \mathrm{Fe}, \mathrm{Ni}, \mathrm{Co})$ was investigated by the sessile drop method.

\section{Experiments}

\section{Materials}

\section{(1) Metal samples}

The metal samples used were $\mathrm{Pb}, \mathrm{Sn}, \mathrm{Al}, \mathrm{Si}$, $\mathrm{Au}, \mathrm{Ge}, \mathrm{Ag}, \mathrm{Fe}, \mathrm{Ni}$ and $\mathrm{Co}$.

Of the metals used, $\mathrm{Pb}, \mathrm{Si}, \mathrm{Au}, \mathrm{Ge}$ and $\mathrm{Ag}$ were of over $99.99 \%$ purity, $\mathrm{Al}, \mathrm{Sn}, \mathrm{Ni}$ and $\mathrm{Co}$ were of over $99.9 \%$, and the $\mathrm{Fe}$ used was electrolyzed $\mathrm{Fe}$ that had been vacuum-melted with a small amount of carbon saturated iron for deoxidation.

\section{(2) SiC samples}

The $\mathrm{SiC}$ samples used were a reaction bond- 
ed $\mathrm{SiC}$ which contained $10 \% \mathrm{Si}$, a hot pressed $\mathrm{SiC}$, and a single crystal of $\alpha$-SiC. Wetting measurement for $\alpha$-SiC was carried out on (0001).

Several experiments were carried out using the reaction bonded $\mathrm{SiC}$ whose surface were treated by carbon. The details of this procedure will be explained in chapter III.

\section{Apparatus and method}

Two types of furnaces were used in this work. The furnace used for the liquid pure metals/reaction bonded $\mathrm{SiC}$ and/hot pressed $\mathrm{SiC}$ systems is shown in Fig. 1(a). The other furnace used in the liquid pure metals/hot pressed $\mathrm{SiC}$ and/single crystal of the $\alpha-\mathrm{SiC}$ system is shown in Fig. 1(b).

Measurements were carried out in an $\mathrm{Ar}$ atmosphere under a reduced pressure.

To avoid the reaction between liquid metals and $\mathrm{SiC}$, the pure metal samples were set in the metal dropping assembly. After attaining the specific temperature, liquid metals were dropped onto SiC substrates. Photographs were then taken at one-minute intervals.

When the contact angle between liquid pure metal and $\mathrm{SiC}$ was an acute one, it was directly obtained from the shape of liquid metal drop

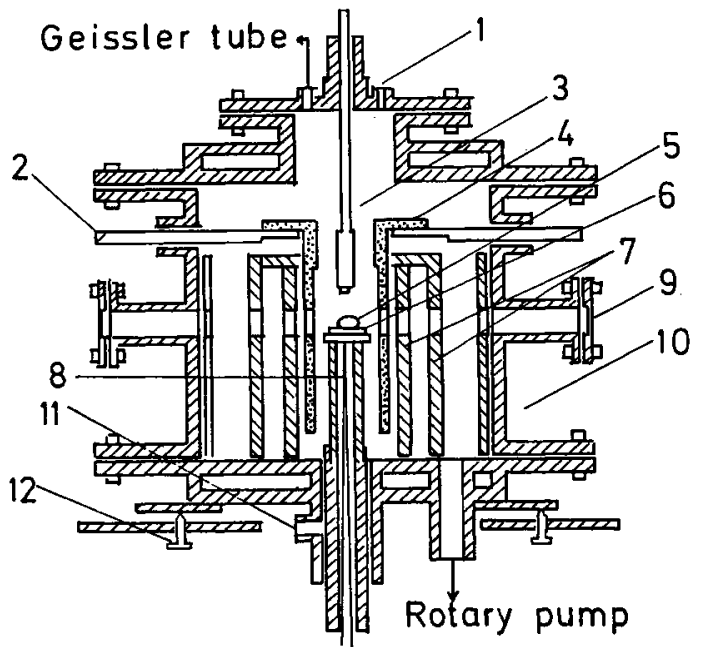

Fig. 1(a) Apparatus for measurement. 1. Gas inlet; 2. Water-cooled electrode, 3. Metal dropping assembly, 4 . Carbon heater, 5. Metal droplet, 6. SiC plate, 7. Alumina refractories, $8 . \mathrm{W} \cdot 5 \mathrm{Re} / \mathrm{W} \cdot 26 \mathrm{Re}$ thermocouple, 9. Observating window, 10. Water cooling pipe, 11. Gas outlet, 12. Levelling screw.

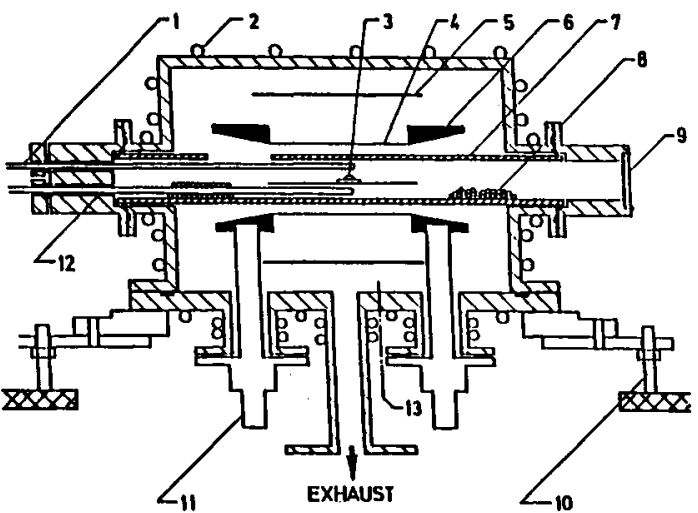

Fig. 1(b) Apparatus for measurement. 1. Metal dropping assembly, 2. Water cooled pipe, 3. Liquid metal drop on $\mathrm{SiC}$, 4. Heating element (carbon net), 5. Mo radiation shield, 6. Graphite ring, 7. Alumina pipe, 8 . Ti shots, 9. Observating window, 10. Levelling screw, 11 . Water cooled copper electrode, 12. Thermocouple, 13. Vacuum gauge.

on the SiC substrate, on the other hand, when it was an obtuse one, it was calculated by Bashforth and Adams' tables ${ }^{(1)}$.

After the experiments, solidified samples were examined by means of optical microscopy and EPMA.

\section{Results and Discussion}

The contact angles between liquid pure metals (Pb, Sn, Al, Si, Au, Ge, Ag, Fe, Ni and $\mathrm{Co}$ ) and $\mathrm{SiC}$ are shown in Figs. $2 \sim 10$. As is clear from Figs. $2 \sim 10$, a difference is observed in the contact angles of liquid pure metals on

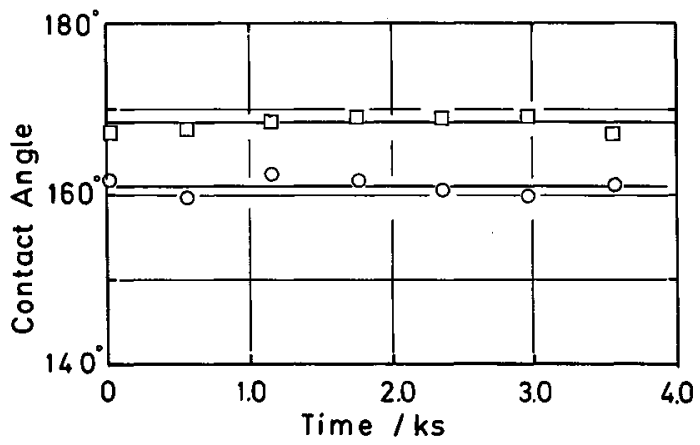

Fig. 2 Time dependence of contact angle of liquid pure $\mathrm{Pb}$ on $\mathrm{SiC}$ at $603 \mathrm{~K}$. $\mathrm{O}$ : Reaction-bonded $\mathrm{SiC}$, $\square$ : Hotpressed SiC. 


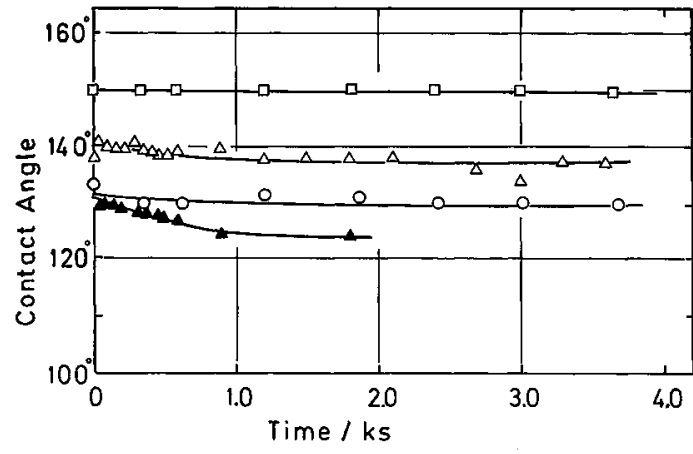

Fig. 3 Time dependence of contact angle of liquid pure $\mathrm{Sn}$ on $\mathrm{SiC}$. O: Reaction-bonded $\mathrm{SiC}$ at $1373 \mathrm{~K}$, $\square$; Hotpressed $\mathrm{SiC}$ at $1373 \mathrm{~K}, \triangle$ : Single crystal of $\alpha-\mathrm{SiC}$ at $1297 \mathrm{~K}, \Delta$ : Single crystal of $\alpha-\mathrm{SiC}$ at $1473 \mathrm{~K}$.

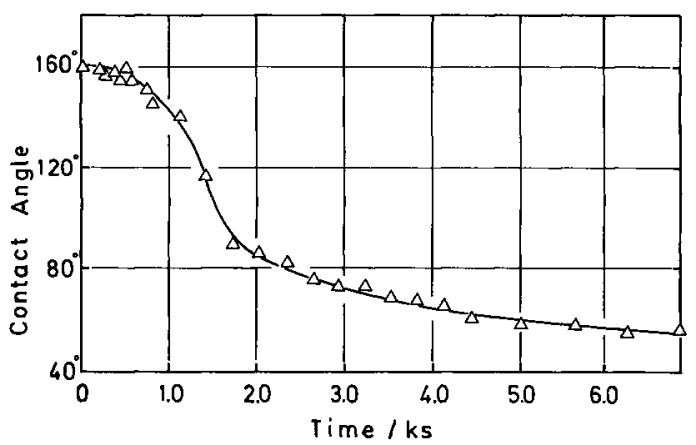

Fig. 4 Time dependence of contact angle of liquid pure $\mathrm{Al}$ on $\alpha-\mathrm{SiC}$ at $1474 \mathrm{~K}$.

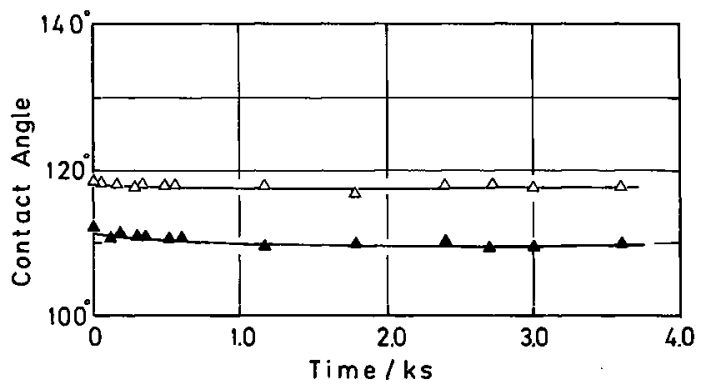

Fig. 5 Time dependence of contact angle of liquid pure Au on $\alpha$-SiC. $\triangle$ : at $1373 \mathrm{~K}, \Delta$ : at $1453 \mathrm{~K}$.

SiC. This is caused not only by the metals employed but also by the $\mathrm{SiC}$ used.

It is obvious from Fig. 2 that the contact angles of liquid $\mathrm{Pb}$ on $\mathrm{SiC}$ show higher values

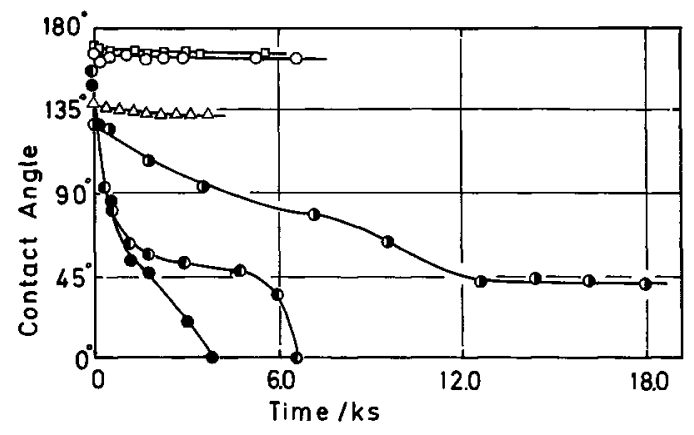

Fig. 6 Time dependence of contact angle of liquid pure $\mathrm{Ge}$ on SiC. O: Reaction-bonded $\mathrm{SiC}$ at $1293 \mathrm{~K}$, O : Reaction-bonded $\mathrm{SiC}$ at $1473 \mathrm{~K}, \mathrm{O}$ : Reaction-bonded $\mathrm{SiC}$ at $1573 \mathrm{~K}$, : Reaction-bonded $\mathrm{SiC}$ at $1693 \mathrm{~K}$, $\square$ : Hotpressed $\mathrm{SiC}$ at $1573 \mathrm{~K}, \triangle$ : Single crystal of $\alpha-\mathrm{SiC}$ at $1503 \mathrm{~K}$.

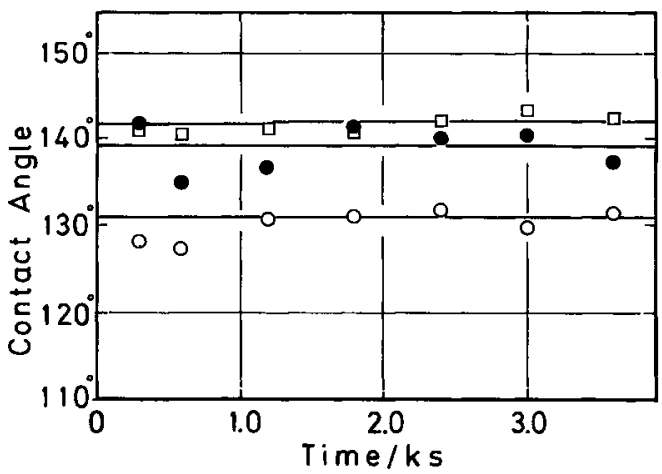

Fig. 7 Time dependence of contact angle of liquid pure $\mathrm{Ag}$ on $\mathrm{SiC}$ at $1283 \mathrm{~K}$. O : Reaction-bonded $\mathrm{SiC}, \bullet$ : Carbon treated reaction-bonded $\mathrm{SiC}, \square$ : Hot-pressed $\mathrm{SiC}$.

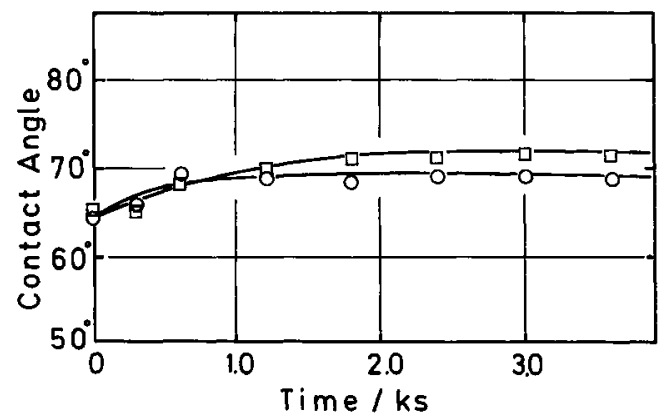

Fig. 8 Time dependence of contact angle of liquid pure $\mathrm{Ni}$ on $\mathrm{SiC}$ at $1773 \mathrm{~K}$. O : Reaction-bonded $\mathrm{SiC}$, $\square$ : Hotpressed $\mathrm{SiC}$. 


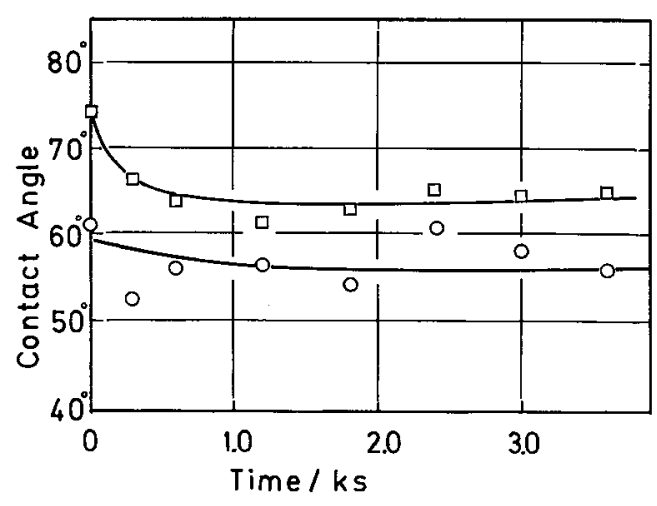

Fig. 9 Time dependence of contact angle of liquid pure Co on $\mathrm{SiC}$ at 1803 K. O: Reaction-bonded SiC, $\square$ : Hotpressed $\mathrm{SiC}$.

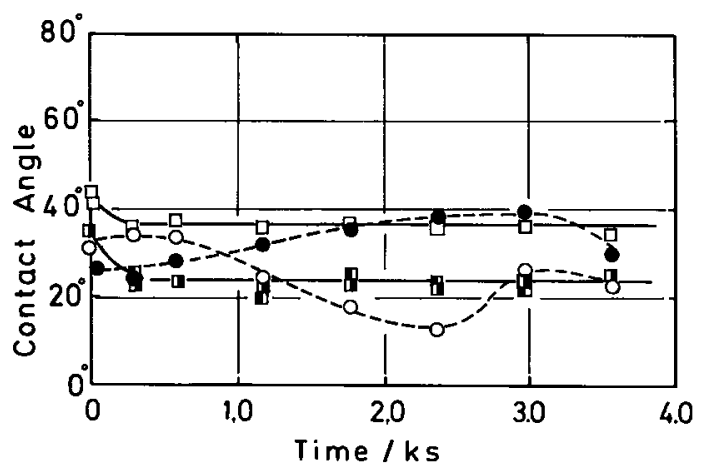

Fig. 10 Time dependence of contact angle of liquid pure $\mathrm{Fe}$ on $\mathrm{SiC}$ at $1873 \mathrm{~K} . \mathrm{O}, \bullet$ : Reaction-bonded $\mathrm{SiC}, \square$, $\mathbf{c}$ a: Hot-pressed SiC.

than $160^{\circ}$ at $603 \mathrm{~K}$ in $\mathrm{Ar}$ atmosphere. No time dependence of contact angle can be observed in the liquid $\mathrm{Pb} / \mathrm{SiC}$ system. This higher angle in both reaction bonded $\mathrm{SiC}$ and hot pressed $\mathrm{SiC}$ can be attributed to the insolubility of $\mathrm{Si}$ or $\mathrm{C}$ in liquid $\mathrm{Pb}^{(2)}$, i.e. the nonreaction between $\mathrm{Pb}$ and $\mathrm{SiC}$.

The time dependence of contact angles of liquid $\mathrm{Sn}$ on $\mathrm{SiC}$ is shown in Fig. 3. As the experimental temperature for a $\mathrm{SiC}$ single crystal differed from that for a reaction bonded SiC and hot pressed $\mathrm{SiC}$, it is difficult to compare the contact angles obtained. It is, however, possible to say that the contact angles depend on the $\mathrm{SiC}$ used. It has generally been reported that the contact angle of liquid metal on ceramics decreases with increasing tempera- ture $^{(3)(4)}$. This tendency has also been observed in liquid metal/ $\mathrm{SiC}$ systems ${ }^{(5)}$.

The difference between the contact angle of liquid $\mathrm{Sn}$ on the hot pressed $\mathrm{SiC}$ and on the reaction bonded $\mathrm{SiC}$ may be observed at 1373 $\mathrm{K}$ from Fig. 3. This may be caused by the dissolution of the Si into liquid Sn which had been contained in the reaction bonded $\mathrm{SiC}$. It has been reported that the solubility of $\mathrm{Si}$ in liquid $\mathrm{Sn}$ in c.a. 2.6 mass $\%$ at the experimental temperature ${ }^{(2)}$.

The contact angle of liquid $\mathrm{Sn}$ on $\mathrm{SiC}$ has been reported by Allen et al. ${ }^{(6)}$ an Naidich ${ }^{(5)}$. Allen et al. reported that the value of the contact angle was $165^{\circ}$ at $1373 \mathrm{~K}$ in $\mathrm{H}_{2}$ atmosphere and in vacuuo and Naidich reported the value as $135^{\circ}$ at $1323 \mathrm{~K}$.

It is difficult to compare the values obtained here with those by Allen et al. and Naidich. However, it is interesting to find that the value for the reaction bonded $\mathrm{SiC}, 131^{\circ}$, is close to that obtained by Naidich and the value for the hot pressed $\mathrm{SiC}, 151^{\circ}$, is close to that by Allen et al.

Time dependence of contact angles of liquid $\mathrm{Al}$ on a single crystal of $\alpha-\mathrm{SiC}$ is shown in Fig. 4. As is clear from Fig. 4, the contact angle of liquid $\mathrm{Al}$ decreased rapidly with the elapse of time. This can be attributed by a formation of $\mathrm{Al}_{4} \mathrm{C}_{3}$ at the interface between liquid $\mathrm{Al}$ and $\mathrm{SiC}$. The reaction between liquid $\mathrm{Al}$ and $\mathrm{SiC}$ can be expressed by eq. $(1)^{(7)}$.

$$
\left.4 \mathrm{Al}(1)+3 \mathrm{SiC}(\mathrm{s})=\mathrm{Al}_{4} \mathrm{C}_{3}(\mathrm{~s})+3 \mathrm{Si} \text { (in liq. } \mathrm{Al}\right)(1)
$$

This reaction was confirmed by a $\mathrm{Si}$ analysis of $\mathrm{Al}$ and an X-ray diffraction analysis for the interface between $\mathrm{Al}$ and $\mathrm{SiC}$ after removing the $\mathrm{Al}$ by $\mathrm{NaOH}$ solution.

The existence of $\mathrm{Al}_{4} \mathrm{C}_{3}$ at the interface was proved by the X-ray diffraction analysis and 8.7 at \% of Si was detected by an EDX analysis of solidified Al sample.

The wettability of $\alpha$-SiC by liquid $\mathrm{Si}$ was measured at $1773 \mathrm{~K}$ under reduced pressure $\left(10^{-3} \mathrm{~Pa}\right)$. Since the liquid Si spread completely over the $\alpha$-SiC, the contact angle could not be determined.

As shown in Fig. 5, the contact angle of liquid $\mathrm{Au}$ on $\alpha$-SiC was almost constant during 
the experiments. This is the same tendency as in the case of liquid Sn.

The effects of temperature and time on the contact angle of liquid $\mathrm{Ge}$ on various $\mathrm{SiC}$ are summerized in Fig. 6. The time dependence of the contact angle differed according to $\mathrm{SiC}$ used. The contact angles on the hot pressed $\mathrm{SiC}$ and the single crystal of $\alpha$-SiC did not change with time. On the other hand, the contact angle on the reaction bonded $\mathrm{SiC}$ changed considerably with time, particularly at higher temperatures.

The interface between solidified $\mathrm{Ge}$ and $\mathrm{SiC}$ was examined by EPMA. It was observed that $\mathrm{Ge}$ had penetrated the reaction bonded $\mathrm{SiC}$ along the grain boundaries where the metallic Si had existed. On the other hand, no penetration of Ge was observed when the hot pressed $\mathrm{SiC}$ and the single crystal of $\alpha-\mathrm{SiC}$ had been used. The penetration depth through the reaction bonded $\mathrm{SiC}$ depended on experimental temperature. No penetration was observed at $1293 \mathrm{~K}$ and Ge penetrated to the bottom of the reaction bonded $\mathrm{SiC}$, whose thickness had been $3 \mathrm{~mm}$, at temperatures higher than 1573 K.

Si contents in the solidified Ge samples were determined by EDX analyses. No $\mathrm{Si}$ was detected in the samples on the hot pressed $\mathrm{SiC}$ and on the single crystal of $\alpha$-SiC. Si contents on the reaction bonded SiC were 0.9, 34.5 and 47.6 at $\%$ at 1293,1473 and $1673 \mathrm{~K}$, respectively. The difference in Si content in the samples and in the behavior of $\mathrm{Ge}$ at the interface between $\mathrm{Ge}$ and $\mathrm{SiC}$ could be the reason for the difference in the time dependence of contact angles.

Kinoshita et al. proposed to use $\mathrm{Ge}$ as a reagent for metal-SiC joining ${ }^{(8)}$. The results obtained here supports their proposal if the reaction bonded $\mathrm{SiC}$ is used.

The time dependence of contact angle of liquid $\mathrm{Ag}$ on $\mathrm{SiC}$ at $1283 \mathrm{~K}$ is shown in Fig. 7. It is clear from Fig. 7 that the contact angle of liquid $\mathrm{Ag}$ on $\mathrm{SiC}$ depends on the properties of the $\mathrm{SiC}$ used. The contact angle on the carbon treated reaction bonded $\mathrm{SiC}$, whose surface was carburated, was not close to that on the reaction bonded $\mathrm{SiC}$ but to that on the hot pressed SiC. The carbon treated reaction bond- ed $\mathrm{SiC}_{\text {was }}$ prepared by heating a reaction bonded $\mathrm{SiC}$ with graphite powder for $5.4 \mathrm{ks}$ at $1573 \mathrm{~K}$ in Ar atmosphere. After the treatment, $\mathrm{X}$-ray diffraction analysis revealed that free $\mathrm{Si}$ did not exist at the surface of the sample. This could be the reason that the value of contact angle on the carbon treated reaction bonded $\mathrm{SiC}$ was close to that on the hot pressed $\mathrm{SiC}$. Si contents of the samples after experiments were determined by EDX and it was found that the Si content in Ag sample which was melted on the reaction bonded $\mathrm{SiC}$ was 4.8 at $\%$ and no $\mathrm{Si}$ was detected in both of the samples which were melted on the hot pressed $\mathrm{SiC}$ and the carbon treated reaction bonded $\mathrm{SiC}$.

These facts suggest that a surface property of the carbon treated reaction bonded $\mathrm{SiC}$ is analogous to that of the hot pressed $\mathrm{SiC}$. It might be possible to protect the reaction bonded $\mathrm{SiC}$ from a reaction with liquid metal by the carbon treatment.

Naidich $^{(5)}$ reported the contact angle of liquid $\mathrm{Ag}$ on $\mathrm{SiC}$ was $128^{\circ}$ at $1373 \mathrm{~K}$. It is difficult to compare the values obtained here with the values of Naidich, since the experimental conditions are not the same. However, it is still possible to say that the value obtained by Naidich is close to that for the reaction bonded $\mathrm{SiC}$. This coincidence was also found in the liquid $\mathrm{Sn} / \mathrm{SiC}$ system described before. Accordingly, the $\mathrm{SiC}$ used by Naidich might be a reaction bonded $\mathrm{SiC}$.

The time dependence of contact angles of liquid $\mathrm{Fe}, \mathrm{Co}$ and $\mathrm{Ni}$ on $\mathrm{SiC}$ is shown in Figs. $8 \sim 10$.

The values of the contact angles themselves shown in Figs. 8 10 and their time dependence differed from those of the other liquid metals such as $\mathrm{Pb}, \mathrm{Sn}, \mathrm{Al}, \mathrm{Au}, \mathrm{Ge}$ and $\mathrm{Ag}$. This can be attributed to the fact that these metals can solve a considerable amount of $\mathrm{Si}$ and $\mathrm{C}$ at the experimental temperature ${ }^{(2)}$.

The difference in the values of the contact angle may be seen in Figs. $8 \sim 10$. The lowest value of a contact angle was observed in the liquid $\mathrm{Fe} / \mathrm{SiC}$ system and the highest in the liquid $\mathrm{Ni}$ / $\mathrm{SiC}$ system.

This may be caused mainly by a difference in the experimental temperature among the systems. It is reasonable to consider that the 
higher the temperature, the more vigorous the reaction between liquid metals and $\mathrm{SiC}$. The reaction between various solid metals and $\mathrm{SiC}$ has been reported previously ${ }^{(9)(10)}$. Though the metals used here are in a liquid form, the results obtained are consistent with those of previous works ${ }^{(9)(10)}$.

It can be said that the contact angles of liquid metals on $\mathrm{SiC}$ are remarkably affected by the dissolution reaction of $\mathrm{Si}$ and $\mathrm{C}$ into the liquid metals and carbide formation reaction at the interface between liquid metals and $\mathrm{SiC}$.

\section{Conclusion}

The wettability of three kinds of $\mathrm{SiC}$, a reaction bonded $\mathrm{SiC}$, a hot pressed $\mathrm{SiC}$ and a single crystal of $\alpha-\mathrm{SiC}$, by liquid pure metals were measured using the sessile drop method.

(1) Contact angles of liquid pure $\mathrm{Pb}, \mathrm{Sn}$, $\mathrm{Au}$ and $\mathrm{Ag}$ were always larger than $90^{\circ}$ for all types of $\mathrm{SiC}$ examined.

(2) The reactivity of a reaction bonded SiC with liquid metal may be controlled by a carbon treatment.

(3) Contact angles of liquid pure $\mathrm{Fe}$, Co and $\mathrm{Ni}$ were always less than $90^{\circ}$ for both reaction bonded $\mathrm{SiC}$ and hot pressed SiC. $\alpha-\mathrm{SiC}$ changed considerably with the elapse of time. The initial contact angle was $160^{\circ}$, reducing gradually with time, the final one after $6.9 \mathrm{Ks}$ was $56^{\circ}$.

(4) Contact angle of liquid pure $\mathrm{Al}$ on a single crystal of $\alpha-\mathrm{SiC}$ changed considerably with time elapsing. The initial contact angle was $160^{\circ}$, reducing gradually with time, the final one after $6.9 \mathrm{ks}$ was $56^{\circ}$. This can be attributed by a formation of $\mathrm{Al}_{4} \mathrm{C}_{3}$ at the inter- face between liquid $\mathrm{Al}$ and $\mathrm{SiC}$.

(5) Contact angle of liquid pure Ge depended on the kind of SiC used. The contact angle on a hot pressed $\mathrm{SiC}$ and $\alpha-\mathrm{SiC}$ was obtuse, on the other hand, that on a reaction bonded $\mathrm{SiC}$ was acute.

(6) Wetting behavior of liquid metals on $\mathrm{SiC}$ is closely related to the solubility of $\mathrm{Si}$ and C.

\section{Acknowledgments}

Authors greatly appreciate Mr. H. Kumon and Mr. K. Ikeda for their devoted experimental work and a financial support by a Grant-inAid for Scientific Research from the Ministry of Education, Science and Culture, Japan.

\section{REFERENCES}

(1) F. Bashforth and A. C. Adams: An Attempt to Test the Theories of Capillary Action, Cambridge Univ. Press (1883).

(2) M. Hansen: Constitution of Binary Alloys, 2nd Ed. McGraw Hill, New York, (1958).

(3) K. Nogi, K. Oishi and K. Ogino: J. Japan Inst. Metals, 52 (1988), 72.

(4) L. Ramqvist: Intern. J. of Powder Met., 1 (1965), No. $4,2$.

(5) Yu. V. Naidich: Kontaktnie Iavlenia v Metallitscheskikh Rasplavakh, Naukova Dumka, Kiev, (1972), p. 172.

(6) B. C. Allen and W. D. Kingery: Trans. Met. Soc. AIME, 215 (1959), 30.

(7) W. Kohler: Aluminum, 51 (1975), 443.

(8) M. Kinoshita: Yogyo-Kyokai-Shi, 89 (1981), No. 6, 30.

(9) K. Nogi, T. Kato and K. Ogino: will be published in this Journal.

(10) R. L. Mehan and M. R. Jackson: Surface and Interfaces in Ceramics and Ceramic-Metal Systems, Ed. by J. A. Pask and A. Evans, Plenum Press, New York and London, (1981), p. 513. 